\title{
Potencial poluidor de agroindústria de produção de queijo sobre o rio Piancó, Pom- bal, Paraíba
}

\section{Potential polluter of an agro-industry of cheese production on the Piancó river, Pombal, Paraíba}

\author{
Sanduel Oliveira de Andrade ${ }^{1}$; Andréa Maria Brandão Mendes de Oliveira ${ }^{2}$; Luiz Fernando de Oliveira Coelho ${ }^{3}$ Célia Soares \\ de Brito ${ }^{4}$, Rayan Araújo Valério 5
}

\begin{abstract}
Resumo: As ações antrópicas têm ocasionado consideráveis impactos negativos na qualidade da água, tornando-a um bem escasso. Este fato é agravado no semiárido nordestino brasileiro, onde a disponibilidade de água é bastante limitada em virtude de suas condições climáticas. O setor rural nordestino possui grande expressividade na economia local, com destaque as agroindústrias. Estas agroindústrias têm gerado grande volume de efluente e grande parte não recebem o tratamento devido, podendo ser lixiviados até atingir um corpo hídrico receptor, causando detrimento da qualidade de suas águas. Diante o exposto, objetivou-se avaliar o potencial poluidor de uma agroindústria de produção de queijo sobre o rio Piancó, município de Pombal, Paraíba. A pesquisa foi desenvolvida no período de maio de 2014 a dezembro de 2015 sendo coletadas amostras do efluente bruto e das águas do rio Piancó, adjacentes a agroindústria e realizadas análises físico-química e microbiológica. Foi possível observar que a agroindústria, mesmo de pequeno porte, possui um elevado potencial poluidor pela grande carga orgânica presente, bem como no lançamento diretamente no meio ambiente sem qualquer tratamento prévio, podendo contaminar corpos hídricos subterrâneos. O efluente gerado não atingiu diretamente o rio, possivelmente, ocasionado pela forte estiagem que atinge a região. Entretanto, nos períodos chuvosos, eleva-se as chances deste poluente ser lixiviado para o rio.
\end{abstract}

Palavras-chave: Efluente; Saneamento; Produção familiar; Semiárido.

\begin{abstract}
The human actions have caused significant negative impacts on water quality, making it a scarce commodity. This fact is compounded in the Brazilian semi-arid northeast, where water availability is quite limited due to its climatic conditions. The northeastern rural sector has great expressiveness in the local economy, especially the agro-industry. These agro-industries have generated large volumes of effluent and most do not receive proper treatment, can be washed up to a water body receptor, causing the detriment of the quality of its waters. On the exposed-to, objective it is through this research to evaluate the potential polluter of an agro-industry cheese production over the Piancó river, municipality of Pombal-Paraíba. The research was conducted from May 2014 to December 2015 where samples were collected from the raw wastewater and water of Piancó river adjacent of the agro-industry and made physicochemical and microbiological analysis It was concluded that the agricultural industry, although small, has a high pollution potential for the high organic load present, as well as to launch directly into the environment without any prior treatment and contaminate underground water bodies. It was also possible to conclude that the effluent does not directly reached the river, possibly caused by severe drought that reaches the region. However, the rainy season, rises the chances of this pollutant to be leached into the river.
\end{abstract}

Key words: Wastewater, Sanitation, Family production, Semiarid.

\footnotetext{
*Autor para correspondência

Recebido para publicação em 13/03/2016; aprovado em 25/11/2016

${ }^{1}$ Engenheiro Agrônomo. Universidade Federal de Campina Grande (UFCG); Especialista em Geoprocessamento. Faculdades Integradas de Patos (FIP); Especialista em Educação Ambiental e Geografia do Semiárido. Instituto Federal do Rio Grande do Norte (IFRN). Mestrando em Sistemas Agroindustriais. Universidade Federal de Campina Grande (UFCG). E-mail: sanduelandrade@ hotmail.com

${ }^{2}$ Engenharia Química, Professora Doutora - Universidade Federal de Campina Grande - UFCG/UACTA, Campus Pombal PB - Rua Jairo Viera Feitosa, n 1770, Bairro dos Pereiros, CEP: 58840-000. E-mail: andrea.maria@ufcg.edu.br

${ }^{3}$ Técnico em Química - Universidade Federal de Campina Grande - UFCG/UACTA, Campus Pombal PB - Rua Jairo Viera Feitosa, n 1770, Bairro dos Pereiros, CEP: 58840-000. E-mail: luisfoc@ ccta.ufcg.edu.br

${ }^{4}$ Graduanda em Engenharia Ambiental. Universidade Federal de Campina Grande - UFCG. E-mail: celiaeng.ambiental@gmail.com

${ }^{5}$ Graduando em Engenharia Ambiental. Universidade Federal de Campina Grande - UFCG. E-mail: rayanaraujov@gmail.com
} 


\section{INTRODUÇÃO}

A agroindustrialização tem surgido como opção promissora no beneficiamento dos produtos agrícolas e, consequentemente, agregando valor a estes, além de absorver os trabalhadores rurais, permitindo-lhes incrementar sua renda (BORTOLUZZI, 2013).

A grande maioria das agroindústrias é de natureza familiar, trabalhando com beneficiamento de frutas, legumes, hortaliças, grãos, oleaginosas, carne, leite e pescados. Geralmente são beneficiados de forma artesanal e informal, sediada em simples instalações (NAIME et al., 2009).

O Brasil vem apresentando constante crescimento na produção de leite, sendo que, em 20 anos, sua produção cresceu 103,1\%. (IBGE, 2012 apud FILHO; SILVA, 2013)

O IBGE (2015) destaca que apenas no $1^{\circ}$ trimestre de 2015, a aquisição de leite por laticínios foi de 6,128 bilhões de litros. Entretanto, devem-se levar em consideração que esses números são os que foram contabilizados pela Inspeção Sanitária, visto que esses números podem aumentar em virtude de um número considerável de agroindústrias operarem na informalidade, principalmente as agroindústrias familiares.

De acordo com Ramasamy e Abbase (2000) uma indústria de beneficiamento de leite possui uma exigência de água para lavagem e limpeza na ordem de 2 a 5 litros por litro de leite utilizado. Com isso, o volume de efluentes gerado é bastante elevado, possuindo uma elevada concentração de matéria biodegradável.

Janczukowicz et al. (2008) afirmam que todos os efluentes gerados no decorrer da cadeia produtiva de produção de queijo podem ser tratados juntos, com exceção do soro de leite, devido a sua alta concentração orgânica e complexa biodegradação. Efluentes com elevada carga orgânica poderá causar inúmeros inconvenientes ao meio ambiente. A lactose e a gordura presente no efluente podem ser consideradas uns dos maiores responsáveis pela elevação dos níveis de Demanda Química de Oxigênio (DQO) e Demanda Bioquímica de Oxigênio (DBO), podendo provocar eutroficação em rios e lagos.

Diante do exposto, objetivou-se avaliar o potencial poluidor de uma agroindústria de produção de queijos no rio Piancó, município de Pombal no Estado da Paraíba.

\section{MATERIAL E MÉTODOS}

O trabalho foi realizado nas agroindústrias familiares localizadas às proximidades do trecho perenizado do rio $\mathrm{Pi}$ ancó no município de Pombal (PB), destacado na Figura 1, durante o período de maio de 2014 a novembro de 2015.

O município de Pombal (PB) situa-se a $06^{\circ} 45^{\prime}$ de latitude sul e $37^{\circ} 48^{\prime}$ de longitude oeste e uma altitude de 175 $\mathrm{m}$, sendo inserido na unidade geoambiental da Depressão Sertaneja, que representa a paisagem típica do semiárido nordestino, caracterizada por uma superfície de pediplanação bastante monótona, relevo predominantemente suaveondulado, cortada por vales estreitos, com vertentes dissecadas. Elevações residuais, cristas e/ou outeiros pontuam a linha do horizonte. Esses relevos isolados testemunham os ciclos intensos de erosão que atingiram grande parte do sertão nordestino (BELTRÃO, 2005).

O clima é o Aw', segundo a classificação de Köppen, semiárido, com chuvas de verão e outono e a precipitação pluviométrica média anual de $800 \mathrm{~mm}$, com variabilidade intra-anual, sendo os meses de fevereiro, março e abril os que mais chovem, concentrando 60 a $80 \%$ do total da precipitação anual. Possui temperaturas médias mensais variando de 23,40 a $27,90^{\circ} \mathrm{C}$; com máximas mensais de $35,70^{\circ} \mathrm{C}$ em dezembro, e mínimas de $19,30^{\circ} \mathrm{C}$, em julho e agosto (MOURA, 2007).

Figura 1. Mapa da localização do trecho perenizado do rio Piancó. Pombal, Paraíba

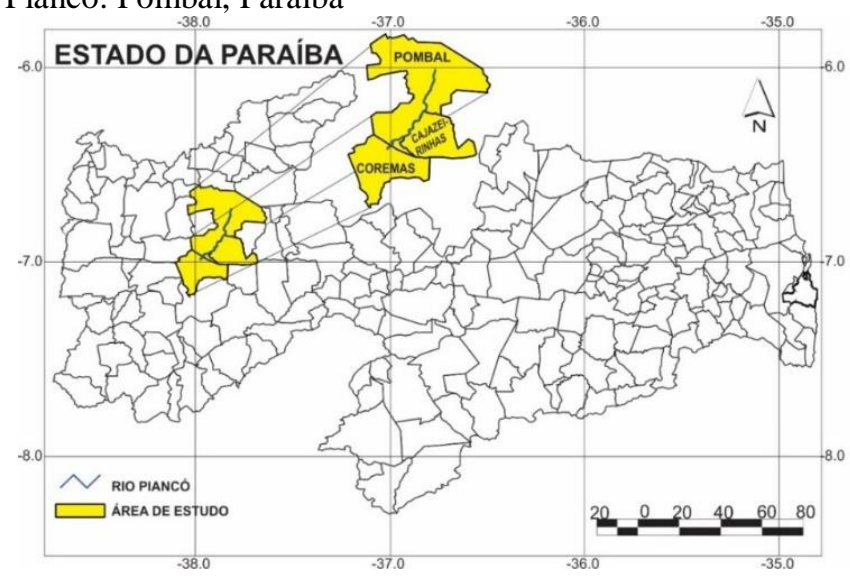

Fonte: Autor (2016).

Entretanto, os últimos anos, a região semiárida tem enfrentado uma grave crise hídrica em virtude da diminuição da precipitação, que vem comprometendo os níveis dos reservatórios e a vazão dos rios desta região. Segundo dados da EMATER-PB (2015), no ano de 2012 choveu apenas 278,9 $\mathrm{mm}$. O pior cenário se dá no segundo semestre de cada ano, onde a precipitação tem sido insignificante, conforme descrito na Figura 2.

Figura 2. Registro pluviométrico de 2012 a 2015 no município de Pombal, Paraíba.

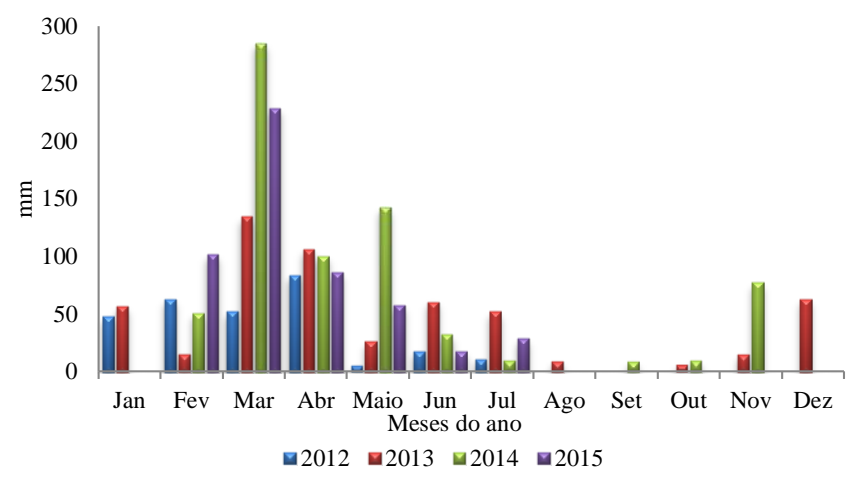

Fonte: EMATER (2015).

Ao analisar a precipitação pluviométrica do município de Pombal apenas no ano de 2015 é possível observar uma maior concentração de chuvas no período de março e desde o mês de julho não tem chovido na região (Figura 3).

Foram realizadas observações visuais nas áreas de produção agroindustrial e aplicados questionários com o responsável pela produção. Por fim, foi descrito o fluxograma da cadeia produtiva dos produtos gerados. Antes da aplicação do questionário, os entrevistados foram informados sobre o objetivo do estudo, resguardando o direito dos mesmos em não participarem. 
Figura 3. Registro pluviométrico de 2015 no município de Pombal, Paraíba

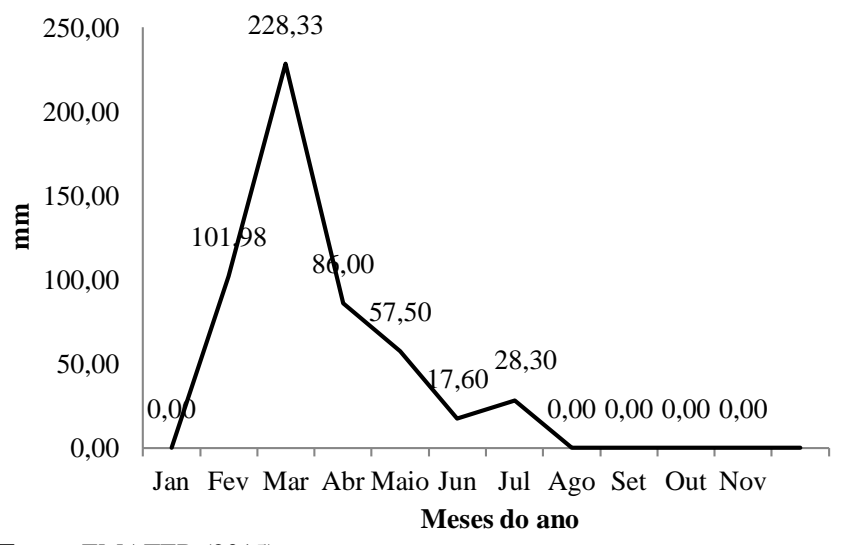

Fonte: EMATER (2015)
Foram realizadas coletas de água tanto a montante quanto a jusante das agroindústrias, georreferenciando todos os pontos, e enviadas para o Laboratório de Análise de Água da Universidade Federal de Campina Grande, Campus de Pombal, no intuito de verificar a qualidade físico-química e microbiológica da água de cada ponto estudado.

Os parâmetros físico-químicos avaliados nos efluentes e na água do rio foram: Temperatura, Cor Aparente e Verdadeira, Turbidez, pH, Nitrogênio Orgânico (N-org), Fósforo (P), Potássio (K), Sódio (Na), Sólidos Sedimentáveis (SS), Sólidos Totais (ST), Sólidos Totais Fixos (STF), Sólidos Totais Voláteis (STV), Condutividade Elétrica (CE), Oxigênio Dissolvido (OD), Demanda Bioquímica de Oxigênio (DBO) e Demanda Química de Oxigênio (DQO). Os parâmetros microbiológicos avaliados nos efluentes e na água do rio foram: Coliformes Totais, Coliformes Termotolerantes e Escherichia coli. As metodologias adotadas estão sintetizadas na Tabela 1.

Tabela 1. Identificação da metodologia utilizada para análise das águas.

\begin{tabular}{ll}
\hline Parâmetro & Método \\
\hline Temperatura & Leitura direta - Hanna HL 9869 \\
Cor Aparente & Leitura direta \\
Verdadeira & Leitura direta \\
Turbidez & Leitura direta - Policontrol AP2000 \\
pH & Leitura direta - Hanna HL 9869 \\
Nitrogênio Orgânico (N-org) & Método Semimicro Kjeldahl ABNT NBR 13796 \\
Potássio (K) & Método da espectrofotometria por emissão em chama \\
Sódio (Na) & Método da espectrofotometria por emissão em chama \\
Sólidos Sedimentáveis (SS) & Cone de Imhoff \\
Sólidos Totais (ST) & SABESP NTS 013 \\
Sólidos Totais Fixos (STF) & SABESP NTS 013 \\
Sólidos Totais Voláteis (STV) & SABESP NTS 013 \\
Condutividade Elétrica (CE) & Leitura direta - Hanna HL 9869 \\
Oxigênio Dissolvido (OD) & Leitura direta - Hanna HL 9869 \\
Demanda Bioquímica de Oxigênio (DBO) & Método padrão sem semeadura (APHA, 1995) \\
Demanda Química de Oxigênio (DQO) & Método da refluxação fechada (PROSAB, 1999) \\
Microbiologia & Técnica de tubos múltiplos. FUNASA (2009) \\
\hline
\end{tabular}

Durante os meses de junho a novembro de 2015 foram coletados $1.500 \mathrm{ml}$ de amostras do efluente bruto e das águas rio Piancó para análise. As amostras do efluente foram coletadas no início e final da produção. As amostras do rio Piancó foram coletadas duas vezes ao dia nos horários de 7 e 15 horas, $20 \mathrm{~m}$ da jusante e montante.

As análises de temperatura, $\mathrm{pH}$ e Oxigênio Dissolvido do efluente e das amostras do corpo receptor foram realizadas no momento da coleta. Após a coleta diária, as amostras foram mantidas sob refrigeração para sua preservação e posteriormente colocadas em gelo, acondicionadas em caixas isotérmicas e conduzidas ao laboratório.

Para quantificação do volume de água utilizado pela agroindústria, foi realizado por meio de hidrômetro Elster AMG-09. O volume de água medido representará o volume necessário à fabricação de determinado produto, englobando a higienização antes e depois do processo.

\section{RESULTADOS E DISCUSSÃO}

O consumo médio de água registrado através do hidrômetro foi de 65 litros, valor este justificado pelo pequeno porte da agroindústria estudada e utilizada principalmente na limpeza das instalações e dos utensílios. A fonte hídrica utili- zada é o próprio rio Piancó, sendo realizado apenas o tratamento simples, por meio de cloração. Para Gomes et al. (2012), o consumo médio de água em uma agroindústria de laticínio varia entre 1,0 a 6,0 litros por litro de leite recebido.

Santos et al. (2013) salienta que muitas doenças podem ser transmitidas pela água, por meio de microrganismos patogênicos de origem entérica, animal ou humana. Em virtude disso, é imprescindível o uso de meios eficientes de tratamento da água a ser usada para preparo dos produtos.

Vasconcelos e Silva (2013) destacam a importância do uso da água com características físico-químicas adequadas para evitar problemas em relação à vida útil dos equipamentos, a exemplo de incrustações ou corrosões em equipamentos e utensílios, por exemplo.

Saraiva (2008) enfatiza que o uso de processos e aparatos tecnológicos de produção que visem reduzir o volume de água consumido e, consequentemente, a quantidade de efluente gerado, é de extrema importância para atingir o patamar de desenvolvimento sustentável, preservando o meio ambiente onde está instalada a agroindústria. 
Caracterização do efluente gerado na agroindústria queijeira

Os valores dos parâmetros físico-químicos do efluente da agroindústria de fabricação de queijo estão sintetizados na Tabela 2.

Tabela 2. Valores dos parâmetros do efluente da agroindústria de fabricação de queijo no município de Pombal, Paraíba.

\begin{tabular}{|c|c|c|}
\hline \multirow[t]{2}{*}{ Parâmetros } & \multicolumn{2}{|c|}{ Valores } \\
\hline & Manhã & Tarde \\
\hline Temperatura ${ }^{\circ} \mathrm{C}$ & 33,81 & 37,12 \\
\hline $\mathrm{pH}$ & 6,25 & 5,75 \\
\hline Condutividade Elétrica $\left(\mu \mathrm{s} . \mathrm{cm}^{-1}\right)$ & 45.485 & 37.040 \\
\hline Sólidos Sedimentares (mL.L $\left.{ }^{-1}\right)$ & 5,37 & 5,13 \\
\hline Sólidos Totais $\left(\mathrm{mg} . \mathrm{L}^{-1}\right)$ & 35.562 & 49.339 \\
\hline Sólidos Totais Fixos $\left(\mathrm{mg} . \mathrm{L}^{-1}\right)$ & 18.919 & 23.687 \\
\hline Sólidos Totais Voláteis (mg. $\left.\mathrm{L}^{-1}\right)$ & 16.643 & 25.652 \\
\hline Oxigênio dissolvido $\left(\mathrm{mg} \mathrm{O}_{2} / \mathrm{L}\right)$ & 2,93 & 2,25 \\
\hline Turbidez (NTU) & 4.469 & 8.953 \\
\hline Cor Aparente (uH) & 22.780 & 40.407 \\
\hline Cor Verdadeira $(\mathrm{uH})$ & 13.523 & 31.607 \\
\hline $\mathrm{DBO}\left(\mathrm{mg} \mathrm{O}_{2} \cdot \mathrm{L}^{-1}\right)$ & 89,39 & 79,29 \\
\hline $\mathrm{DQO}\left(\mathrm{mg} \mathrm{O}_{2} \cdot \mathrm{L}^{-1}\right)$ & 13.245 & 28.969 \\
\hline $\mathrm{N}$ org. $\left(\mathrm{mg} . \mathrm{L}^{-1}\right)$ & 49,61 & 61,65 \\
\hline $\mathrm{Na}\left(\mathrm{mg} \cdot \mathrm{L}^{-1}\right)$ & 307,59 & 289,85 \\
\hline $\mathrm{K}\left(\mathrm{mg} . \mathrm{L}^{-1}\right)$ & 30,29 & 26,84 \\
\hline
\end{tabular}

Fonte: Autor (2016)

A temperatura do efluente variou entre $33,81^{\circ} \mathrm{C}$ no turno da manhã a $37,12^{\circ} \mathrm{C}$ durante a tarde. Saraiva (2008), analisando o efluente de uma indústria de laticínio verificou valores aproximados variando de 28 a $38{ }^{\circ} \mathrm{C}$. Para Abrahão (2006), a temperatura, juntamente com a alcalinidade, $\mathrm{pH}$ e Oxigênio Dissolvido são os mais relevantes fatores abióticos que interferem nos processos biológicos e que tem influenciado no desempenho do tratamento dos efluentes.

A Agência Nacional de Águas, ANA (2011) salienta que oscilações na temperatura natural dos corpos hídricos poderá acarretar comprometimento no processo reprodutivo e de crescimento dos organismos aquáticos, provocando decréscimo no número de pescado ou de outra classe de organismos que podem ser explorados economicamente. Essa redução poderá prejudicar o segmento da população que depende desse recurso para geração de renda. Quanto maior a temperatura da água, menor será a concentração de oxigênio, prejudicando as funções metabólicas dos organismos existente nesse ecossistema local.

Nas amostras coletadas do efluente gerado pela agroindústria, apresentou $\mathrm{pH}$ ligeiramente ácido, variando entre 6,25 (no início da produção) a 5,75 (final da produção). Mendonça et al. (2015) destacam que há uma grande variação na faixa de $\mathrm{pH}$ de efluentes de lacínios ( 3 a 11). Fabbi et al. (2011) obtiveram valores entre 5,34 a 7,41 e Lima et al. (2013) de 4,7. Andrade (2011) destacam que o pH poderá sofrer oscilações de faixa em decorrência do uso de produtos de limpeza e sanitização. A elevação da acidez em corpos hídricos poderá afetar organismos mais jovens, pois estes tendem a ser menos tolerantes a $\mathrm{pH}$ mais baixos (ANA, 2011).

No tocante ao solo, $\mathrm{pH}$ mais ácido podem mobilizar metais de solos naturais, a exemplo do alumínio, que ao ser lixiviado para algum corpo hídrico, poderá acarretar intoxica- ção e a morte de determinados organismos aquáticos (ANA, 2011).

A condutividade elétrica encontrada no efluente gerado no início da produção do queijo foi de $45.485 \mu \mathrm{s} . \mathrm{cm}^{-1} \mathrm{e}$ $37.040 \mu \mathrm{s} . \mathrm{cm}^{-1}$ no final da produção, indicando elevadas concentrações de sais. Fato este, agravado pelo despejo direto da salmoura (água + soro + cloreto de sódio) na rede de esgoto. Mendes et al. (2015) constataram valores na ordem de $8.680 \mu \mathrm{s} . \mathrm{cm}^{-1}$ para efluente oriundo da indústria de laticínios.

Para Saraiva (2008), o descarte de elevado volume da salmoura resulta em aumento da carga orgânica e da condutividade, pois esta solução é rica em sólidos suspensos, microrganismos, sais de cálcio, magnésio, lactose e ácido lático.

Na comunidade foi observado que a salmoura produzida na fabricação do queijo coalho é lançada diretamente no solo, representada na Figura 4. Geralmente, espécies vegetais e animais de água doce não toleram elevadas concentrações de sais. Esse acúmulo de sais no solo pode ser lixiviado até um corpo hídrico, seja ele subterrâneo ou superficial. Teores elevados de sais tendem a provocar estresse em organismos de água doce, interferindo em sua função metabólica e nos níveis de saturação de oxigênio. No solo, altas concentrações de sais comprometem a vegetação local, reduz a produtividade agrícola e favorece a desertificação (ANA, 2011).

Figura 4. Salmoura (água + soro + cloreto de sódio) produzida durante a fabricação do queijo coalho.

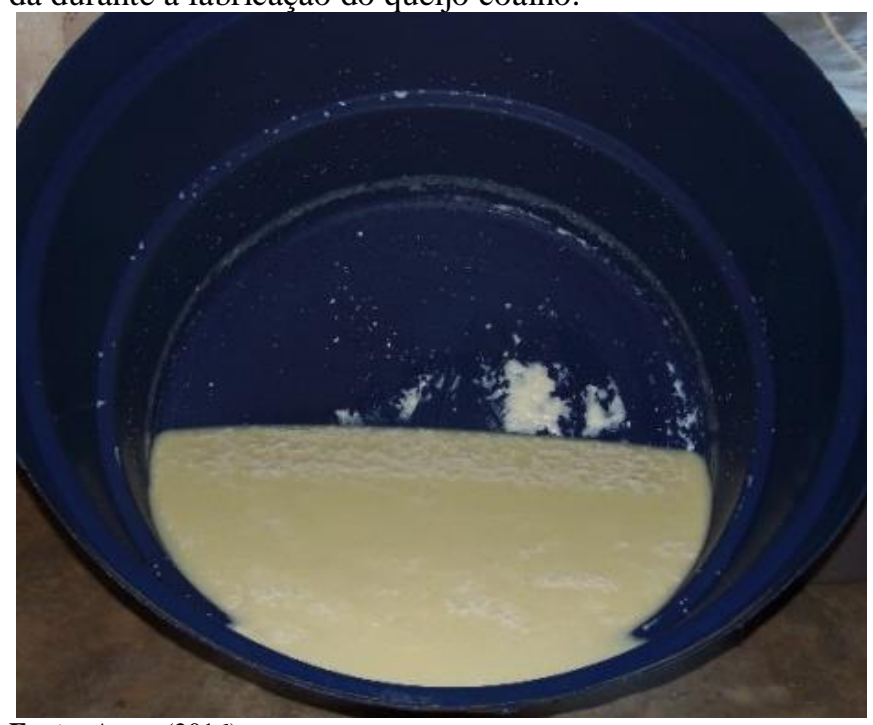

Fonte: Autor (2016)

Os sólidos sedimentáveis variaram entre 5,13 a 5,37 mL.L ${ }^{-1}$. Saraiva (2008) obteve valor médio de $14 \mathrm{~mL} . \mathrm{L}^{-1}$ para efluente de laticínios. O limite estabelecido pela Resolução CONAMA n ${ }^{\circ}$ 430/2011 para lançamento de efluente em corpos hídricos receptores é de $1 \mathrm{~mL} . \mathrm{L}^{-1}$, portanto é possível afirmar que grande parte dos efluentes não estão em consonância com o que estabelece a legislação vigente. Também foi contado um alto teor de Sólidos Totais, variando entre 35.562 a $49.339 \mathrm{mg} . \mathrm{L}^{-1}$, onde cerca de $50 \%$ corresponde a material orgânico. A Legislação CONAMA n ${ }^{\circ}$ 430/2011 estabelece que, para ser lançado ao meio ambiente, a eficiência mínima de remoção dos sólidos suspensos é de $20 \%$, após desarenação.

Os valores referentes à turbidez apresentaram, no início da produção, 4.469 NTU, aumentando consideravel- 
mente no final da produção, chegando a atingir 8.953 NTU, indicando elevada carga de material em suspensão. A Resolução $\mathrm{n}^{\circ} 430 / 2011$ não faz ressalvas quanto aos valores de turbidez para lançamento de efluentes. Entretanto, Pádua (2001) salienta que o teor de turbidez elevado ocasionará uma má aparência visual, elevado os índices de componentes dissolvidos, que vão desde a matéria orgânica até microrganismos patogênicos.

No que diz respeito a cor aparente, no início da produção, o efluente apresentou o valor de $22.780 \mathrm{uH}$, chegando a 40.407 uH no final da produção. Quanto a cor verdadeira, no início da produção, apresentou $13.523 \mathrm{uH}$, e no final, $31.607 \mathrm{uH}$. Verifica-se, portanto, que o efluente continha uma alta concentração de sólidos suspensos, uma vez que a sua cor aparente era bastante superior a real. Andrade et al. (2011) constataram valores entre 1.018,2 a 2.514,2 uH de cor aparente para efluentes de laticínios. Carvalho et al. (2015) relacionam a cor da água a presença de ferro e manganês.

No efluente agroindustrial foi constatado, no início do processo produtivo, o teor de oxigênio dissolvido na ordem de $2,93 \mathrm{mg} \mathrm{O}_{2} \cdot \mathrm{L}^{-1}$, sendo reduzido a $2,25 \mathrm{mg} \mathrm{O}_{2} \cdot \mathrm{L}^{-1}$ no final do processo. Para Abrahão (2006), o OD é influenciado pela temperatura e por sais dissolvidos no efluente.

Quanto a Demanda Bioquímica de Oxigênio (DBO) foi possível observar que esta variou entre 79,29 e 89,39 mg $\mathrm{O}_{2} \cdot \mathrm{L}^{-1}$. Lima et al. (2013) obtiveram valores médios de DBO de $913 \mathrm{mg} \mathrm{O} \mathrm{O}_{2} \mathrm{~L}^{-1}$. Entretanto, Machado et al. (2002) afirmam que os efluentes de laticínios podem atingir patamares mais elevados como $4.000 \mathrm{mg} \mathrm{O}_{2} . \mathrm{L}^{-1}$. Mendes et al. (2015) encontraram valores de DBO em efluente de laticínios na ordem de $29.400 \mathrm{mg} \mathrm{O}_{2} \cdot \mathrm{L}^{-1}$.

Os valores de DQO encontrados no efluente agroindustrial estudado variou de 13.245 a $28.969 \mathrm{mg} \mathrm{O} \mathrm{O}_{2} \cdot \mathrm{L}^{-1}$. Valores divergentes dos encontrados por Brião e Tavares (2015), na ordem de $2.491 \mathrm{mg} \mathrm{O}{ }_{2} \cdot \mathrm{L}^{-1}$ para um efluente agroindustrial de laticínio. Naime et al. (2009) afirmam que o despejo do efluente com alto valor de DQO diretamente ao solo tem elevado as chances de poluição dos corpos hídricos subterrâneos, também levando em consideração a capacidade de infiltração do solo. Mendes et al. (2015) também encontraram valores bem elevados de DQO em efluentes de laticínios, chegando a $224.800 \mathrm{mg} \mathrm{O} \cdot \mathrm{L}^{-1}$.

Os valores de nitrogênio orgânico variaram de 49,61 a 61,65 mg.L ${ }^{-1}$. Naime et al. (2009) destacam que o nitrogênio é um dos elementos fundamentais para criar um ambiente favorável para proliferação de algas, e quando presente em elevadas quantidades em corpos hídricos, acaba por favorecer o desenvolvimento exagerado de microrganismos patogênicos. Associado a outros elementos, poderá levar o corpo hídrico a eutroficação.

Também foi observado uma alta concentração de Sódio (Na) no efluente analisado, variando de 307,59 a $289,85 \mathrm{mg} . \mathrm{L}^{-1}$. Coelho et al. (2013) afirmam que, dependendo da concentração de sódio, pode tornar uma determinada área inviável para exploração agrícola.

Oliveira et al. (2014) salientam que a irrigação realizada com água com excesso de sais poderá acarretar perdas de produtividade e salinização do solo. Oliveira et al. (2011) relatam que o excesso de sais tem provocado efeito negativo nas plantas por estarem associados ao componente de tensão osmótica, ocasionado pela diminuição do potencial de água no solo e pela restrição de absorção de água pelas raízes, reduzindo seu crescimento e sua produtividade, além de ocasionar a queima das folhas.

Bastos et al. (2003) afirmam que quanto maior a salinidade da água, maior será a velocidade de infiltração no solo. Com isso, o efluente lançado pela agroindústria de produção de queijo, poderá atingir em menor espaço tempo o lençol freático, comprometendo sua qualidade.

O teor de Potássio $(\mathrm{K})$ encontrado no efluente variou de 26,84 a $30,29 \mathrm{mg} . \mathrm{L}^{-1}$. A contaminação por excesso de nutrientes em corpos hídricos, além da eutroficação, poderá promover a acidificação de suas águas, causando sérios danos a biodiversidade local (ANA, 2011).

Quanto ao destino dos resíduos sólidos gerados foi possível observar que são compostos basicamente de embalagens plásticas, papéis, embalagens de produtos químicos e aparas de queijos. Os resíduos sólidos gerados no laticínio são queimados no final do dia, em um determinado local, de forma não controlada.

No tocante aos parâmetros microbiológicos foi possível observar uma elevada concentração de coliformes no efluente gerado no processo de fabricação do queijo, conforme destacado na Tabela 3. Suspeita-se que na mesma rede onde são despejados os efluentes agroindustriais também haja efluentes oriundos de banheiros, devido à conjugação da tubulação com a residência do produtor.

Tabela 3. Valores dos parâmetros microbiológicos do efluente da agroindústria de queijos no município de Pombal, Paraíba

\begin{tabular}{lcc}
\hline \multirow{1}{*}{ Parâmetros } & \multicolumn{2}{c}{ Valores } \\
\cline { 2 - 3 } & $\begin{array}{l}\text { Início da } \\
\text { produção }\end{array}$ & $\begin{array}{l}\text { Final da } \\
\text { produção }\end{array}$ \\
\hline Coliformes totais & $8,13 \mathrm{E}+09$ & $7,34 \mathrm{E}+09$ \\
Coliformes termotolerantes & $7,41 \mathrm{E}+09$ & $7,37 \mathrm{E}+09$ \\
Escherichia coli & $1,20 \mathrm{E}+07$ & $1,00 \mathrm{E}+07$ \\
\hline
\end{tabular}

\section{Caracterização da água do rio Piancó nas proximidades da agroindústria}

Os valores dos parâmetros físico-químicos avaliados nas águas do rio Piancó nas proximidades da agroindústria avaliada estão descritos na Tabela 4.

Tabela 4. Valores dos parâmetros das águas do rio Piancó, trecho localizado próximo a agroindústria de produção de queijo no município de Pombal, Paraíba

\begin{tabular}{|c|c|c|}
\hline \multirow[t]{2}{*}{ Parâmetros } & \multicolumn{2}{|c|}{ Valores } \\
\hline & Montante & Jusante \\
\hline Temperatura & 27,75 & 28,39 \\
\hline $\mathrm{pH}$ & 7,77 & 7,71 \\
\hline Condutividade Elétrica $\left(\mu \mathrm{s} . \mathrm{cm}^{-1}\right)$ & 320 & 322,7 \\
\hline Sólidos Sedimentares $\left(\mathrm{mL} . \mathrm{L}^{-1}\right)$ & $<0,10$ & $<0,10$ \\
\hline Sólidos Totais $\left(\mathrm{mg} \cdot \mathrm{L}^{-1}\right)$ & 179,44 & 177,63 \\
\hline Sólidos Totais Fixos (mg. $\left.\mathrm{L}^{-1}\right)$ & 98,13 & 109,25 \\
\hline Sólidos Totais Voláteis $\left(\mathrm{mg} . \mathrm{L}^{-1}\right)$ & 80,31 & 68,38 \\
\hline Oxigênio dissolvido $\left(\mathrm{mg} \mathrm{O}_{2} \cdot \mathrm{L}^{-1}\right)$ & 6,11 & 6,28 \\
\hline Turbidez (NTU) & 1,09 & 1,34 \\
\hline Cor Aparente (uH) & 30,5 & 27,3 \\
\hline Cor Verdadeira $(\mathrm{uH})$ & 23 & 21,8 \\
\hline $\mathrm{DBO}\left(\mathrm{mg} \mathrm{O}_{2} \cdot \mathrm{L}^{-1}\right)$ & 14,24 & 13,29 \\
\hline $\mathrm{DQO}\left(\mathrm{mg} \mathrm{O}_{2} \cdot \mathrm{L}^{-1}\right)$ & 24,2 & 23,6 \\
\hline $\mathrm{N}$ org. $\left(\mathrm{mg} \cdot \mathrm{L}^{-1}\right)$ & 5,13 & 4,76 \\
\hline $\mathrm{Na}\left(\mathrm{mg} \cdot \mathrm{L}^{-1}\right)$ & 1,4 & 1,4 \\
\hline $\mathrm{K}\left(\mathrm{mg} . \mathrm{L}^{-1}\right)$ & 0,31 & 0,31 \\
\hline
\end{tabular}


A temperatura no momento da coleta variou entre 27,75 a $28,39{ }^{\circ} \mathrm{C}$. Os valores médios de $\mathrm{pH}$ encontrados nestes pontos foi de 7,7 , indicando um $\mathrm{pH}$ próximo a neutralidade e dentro dos valores estabelecidos pela CONAMA ${ }^{\circ}$ $357 / 2005$ que tolera uma faixa de $\mathrm{pH}$ entre 6,0 e 9,0 (BRASIL, 2005). Para Naime (2009), alterações na faixa de $\mathrm{pH}$ pode ser um indicativo de algum agente contaminante na água, acarretando problemas quando usada para fazer higienização devido a possibilidade de ocorrer a neutralização de agentes desinfetantes a exemplo do cloro, ou hipoclorito de cálcio e ácido peracético, comumente utilizados

Nas águas do rio Piancó a Condutividade Elétrica variou entre 320 a $322,7 \mu \mathrm{s} . \mathrm{cm}^{-1}$, mostrando que, no período estudado, o efluente agroindustrial ainda não está atingindo diretamente o rio. Lima et al. (2013) destaca que culturas irrigadas cujas águas possuíam uma condutividade elétrica acima de $2.000 \mu \mathrm{s} . \mathrm{cm}^{-1}$ não apresentaram produção satisfatória.

Silva e Sacomani (2001) analisando as águas do Rio Pardo, localizado no município de Botucatu - SP encontraram valores de condutividade da ordem de 17,77 a 39,07 $\mu \mathrm{s} . \mathrm{cm}^{-1}$. Essa discrepância dos valores encontrados por Silva e Sarcomani (2001) em relação ao encontrado nesta pesquisa pode ser pelo fato da composição geológica da área de estudo ser diferente.

De acordo com a CETESB (2009) níveis de condutividade elétrica acima de $100 \mathrm{mS} . \mathrm{cm}^{-1}$ são indicativos de impactos ambientais negativos, provavelmente por origem antrópica.

Os sólidos sedimentáveis em todos os pontos avaliados apresentou menos de $0,1 \mathrm{~mL} . \mathrm{L}^{-1}$, indicando baixa concentração de sólidos em água. Tais valores se enquadram na Legislação CONAMA n ${ }^{\circ}$ 357/2015 que estabelece um limite de $500 \mathrm{mg} . \mathrm{L}-1$ para rios de classe II.

Nas águas do rio Piancó, os resultados do parâmetro cor aparente variou entre 30,5 a 27,3 uH. Na cor verdadeira, houve um sutil decréscimo destes valores, variando entre 21,8 a $23 \mathrm{uH}$.

A resolução CONAMA n ${ }^{\circ}$ 357/2005 não estabelece limites específicos para cor aparente, porém destaca os limites para a cor verdadeira que não deve superar o valor de $75 \mathrm{uH}$ para águas de classe II, portanto, levando em consideração este parâmetro, as águas do Rio Piancó estão condizentes com a legislação atual. Em contrapartida, no quesito potabilidade, a Portaria $n^{\circ}$ 2.914/2011 do Ministério da Saúde estabelece um valor máximo de $15 \mathrm{uH}$ para água potável. A elevação da cor aparente está relacionada ao material em suspensão existente na água enquanto que a cor verdadeira está relacionada a materiais dissolvidos.

Rocha et al. (2015), estudando a qualidade das águas do reservatório de Orós, localizado no Estado do Ceará, verificaram uma variação da cor aparente entre 10 e 200 uH. O referido autor salienta que os picos de cor encontrados ocorreram em virtude da localização de um dos pontos, que ficou próximo a junção com outro rio cujas águas são ricas em matéria orgânica.

A turbidez das águas do rio Piancó variou entre 1,09 e 1,34 NTU, índices em conformidade com a Resolução CONAMA n ${ }^{0} 357 / 2005$ para águas de classe II. A presença de animais e banhistas no rio poderá elevar a presença de material em suspensão nas águas do rio Piancó, fato este constatado nesta pesquisa. Andrade e Macedo (2008) destacam que a turbidez está relacionada ao teor de material em suspensão, a exemplo de plânctons, bactérias, argila, areia e poluição de forma geral.

Os valores relativos a oxigênio dissolvido nas águas do rio Piancó oscilaram entre 6,11 a $6,28 \mathrm{mg} \mathrm{O}_{2} \cdot \mathrm{L}^{-1}$. Valores condizentes com a resolução CONAMA n ${ }^{\circ} 357 / 2005$ que estabelece valores acima de $5 \mathrm{mg} \mathrm{O} \mathrm{O}_{2} \cdot \mathrm{L}^{-1}$ para águas de classe II.

Bellanger et al. (2004) afirmam que quando o oxigênio dissolvido atinge níveis mais baixos que o necessário para biodegradação da matéria orgânica, a qualidade deste corpo hídrico está comprometida.

Silva e Sacomani (2001) enfatizam que o monitoramento da concentração de oxigênio em rios é um assunto bem complexo em virtude dos processos biológicos, físicos e químicos que estão envolvidos nesta variação. Com isso, é imprescindível levar em consideração uma cuidadosa análise das características locais do ambiente em estudo.

A DBO variou entre 13,29 e $14,24 \mathrm{mg} \mathrm{O}_{2} \cdot \mathrm{L}^{-1}$. Sendo assim, está fora da faixa tolerada pela resolução CONAMA $n^{\circ}$ $357 / 2005$ que estabelece o valor máximo de $5 \mathrm{mg} \mathrm{O} \cdot \mathrm{L}^{-1}$.

Rosseti (2009) afirma que valores elevados de DBO pode indicar um aumento da microflora, interferindo no equilíbrio da vida aquática, bem como produzir sabores e odores desagradáveis na água. A presença destas microalgas também poderá acarretar danos a tubulação e a filtros de areia utilizados por estações de tratamento de água.

A DQO dos pontos analisados variou de 23,6 a 24,2 $\mathrm{mg} \mathrm{O}_{2} \cdot \mathrm{L}^{-1}$. Para Naime et al. (2009) a DQO fornece uma indicação da quantidade de oxigênio que será necessária para oxidar completamente os poluentes oriundos de esgotos domésticos ou industriais. A legislação do Conama 357/2005 não estabelece um valor limite para esses parâmetros em rios de classe II.

O teor de N-org nas águas do Piancó nos pontos estudados variou entre 4,76 a 5,13 mg.L $\mathrm{L}^{-1}$. Edwiges e Bollmann (2007), analisando as águas do Rio Belém, Estado do Paraná, verificaram que o Nitrogênio Orgânico apresentou uma variação aproximada de 5,0 a 8,0 mg. $\mathrm{L}^{-1}$.

Para Wetzel, (2001), o Nitrogênio orgânico (N-org) em ecossistemas aquáticos ocorre pela assimilação do nitrogênio inorgânico e pela incorporação por algas e bactérias. Chen et al. (2011) afirmam que, para abastecimento de água potável, os níveis de N-org devem ser inferiores a $0,3 \mathrm{mg}$ N.L ${ }^{-1}$. Os autores também destacam que elevadas concentrações de nitrogênio acarretará na eutroficação do corpo hídrico. Essa forma de nitrogênio também é bastante relevante no solo.

O teor de Sódio (Na) manteve em 1,4 mg.L $\mathrm{L}^{-1}$. Juntamente com o Nitrogênio e o Fósforo, o Potássio contribui expressivamente para aceleração do processo de eutrofização de um determinado corpo hídrico.

O teor de Potássio $(\mathrm{K})$ em $0,31 \mathrm{mg} . \mathrm{L}^{-1}$. A Portaria 2.914/2011 do Ministério da Saúde fixa o valor limite permitido de Sódio em $200 \mathrm{mg} . \mathrm{L}^{-1}$, portanto as águas do rio Piancó nos pontos avaliados estão em conformidade com a legislação vigente.

A contaminação por excesso de nutrientes tem se tornado um problema constante nos corpos hídricos a nível global. A UN WWAP (2015) relaciona o nitrogênio e o fósforo como os principais responsáveis pelo incremento de nutrientes em corpos hídricos e que geralmente são oriundos de efluentes domésticos e/ou industriais. $\mathrm{O}$ excesso destes nutri- 
entes tende a elevar a taxa de produção primária gerando um supercrescimento de plantas vasculares.

Nos trechos do rio analisado foi contatada uma elevada presença de aguapés (Eichhornia crassipes), conforme mostra a Figura 5. O excesso de espécies aquáticas acarretará na redução do oxigênio dissolvido na coluna de água, provocando estresse ou até a morte destas espécies.

Figura 5. Elevada concentração de aguapés (Eichhornia crassipes) no Rio Piancó, Pombal, Paraíba

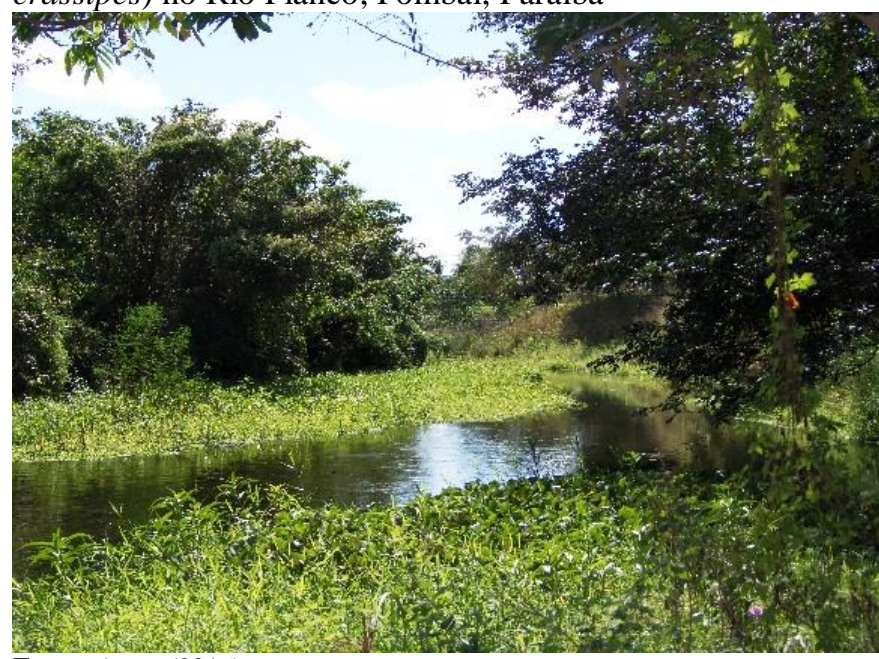

Fonte: Autor (2016)

Os resultados também comprovam que no trecho avaliado, a água do rio Piancó está imprópria para o uso em virtude da elevada concentração de coliformes totais e termotolerantes, bem como a presença da bactéria Escherichia coli, conforme demostrado na Tabela 5. A Legislação CONAMA $n^{0} 357 / 2005$ estabelece um limite de 1.000 coliformes termotolerantes por $100 \mathrm{ml}$.

Tabela 5. Valores dos parâmetros microbiológicos do rio Piancó no trecho localizado próximo a agroindústria de queijo no município de Pombal, Paraíba.

\begin{tabular}{lcc}
\hline \multicolumn{1}{c}{ Parâmetros } & \multicolumn{2}{c}{ Valores } \\
\cline { 2 - 3 } & Montante & Jusante \\
\hline Coliformes Totais & $6,42 \mathrm{E}+04$ & $4,65 \mathrm{E}+04$ \\
Coliformes Termotolerantes & $7,53 \mathrm{E}+04$ & $4,37 \mathrm{E}+04$ \\
Escherichia coli & $1,60 \mathrm{E}+04$ & $3,56 \mathrm{E}+02$ \\
\hline
\end{tabular}

De acordo com Müller e Parussolo (2014), o grupo dos coliformes totais é composto por bacilos Gram-negativos não esporulados pertencentes à família Enterobacteriacea, que fermentam a lactose com formação de gás quando incubados à $37^{\circ} \mathrm{C}$ por $24-48$ horas e seus principais representantes são as bactérias dos gêneros Escherichia, Enterobacter, Citrobacter e Klebsiella. Os coliformes termotolerantes são aqueles coliformes totais que apresentam a capacidade de continuar fermentando a lactose, com formação de gás, em temperatura de $44-45^{\circ} \mathrm{C}$ em 24 horas, sendo a bactéria Escherichia coli a principal representante desse grupo. Além disso, essa bactéria pode ser utilizada para indicar uma possível contaminação fecal da água, pois E. coli é um microrganismo encontrado na microbiota intestinal de animais.

\section{CONCLUSÕES}

A agroindústria de produção de queijos, mesmo sendo de pequeno porte, possui um elevado potencial poluidor devido à grande carga orgânica presente, bem como no lançamento diretamente no meio ambiente sem qualquer tratamento prévio.

O maior risco de poluição nas linhas de produção do queijo é a salmoura, em termos de volume e matéria orgânica no efluente final e por apresentar elevada concentração matéria orgânica e sódio.

O efluente gerado ainda não atingiu diretamente o rio Piancó. A grave estiagem que assola o semiárido nordestino nos últimos quatro anos pode ter evitado o contato direto do efluente com o referido rio, cuja vazão encontra-se reduzida. Entretanto, nos períodos chuvosos, elevam-se as chances deste poluente ser lixiviado para o rio.

\section{REFERÊNCIAS}

ABRAHÃO, S. S. Tratamento de água residuária de laticínios em sistemas alagados construídos cultivados com forrageiras. Mestrado, Universidade Federal de Viçosa. Viçosa, 2006.

ANA. Agência Nacional das Águas. Cuidando das águas: soluções para melhorar a qualidade dos recursos hídricos. Programa das Nações Unidas para o Meio Ambiente. Brasília, 2011. 154p. Disponível em: $<$ http://www.sswm.info/sites/default/fi-

les/reference_attachments/ANA\%202011\%20Cuidando\%20d as\%20águas\%20-\%20PORTUGUESE.pdf>. Acesso em: 30 set. 2015.

ANDRADE, L. H. Tratamento de efluente de indústria de laticínios por duas conFigurações de biorreator com membranas e nanofiltração visando o reuso. Dissertação (mestrado) Universidade Federal de Minas Gerais, Escola de Engenharia. 2011. 214p.

ANDRADE, N. J.; MACEDO, J.A.B. Higienização na Indústria de Alimentos. São Paulo: Livraria Varela, 2008. p. 182.

BASTOS, R. K. X.; MARQUES, M. O. Utilização de esgoto tratado em fertirrigação, hidroponia e piscicultura-Uma análise crítica. Rio de Janeiro: ABES, RiMa, 2003, 247-253.

BELLANGER, B.; HUON, S.; STEINMANN, P.; CHABAUX, F.; VELASQUEZ, F.; VALLÈS, V.; ARN, K.; CLAUER, N.; MARIOTTI, A. Oxic-anoxic conditions in the water column of a tropical freshwater reservoir (Pena-Larga dam, NW Venezuela). Applied Geochemistry, 19, 2004. 1295-1314.

BELTRÃO, B. A.; MORAIS, F.; MASCARENHAS J. C.; MIRANDA J. L. F.; JÚNIOR L. C. S.; MENDES V. A. Projeto Cadastro de Fontes de Abastecimento por Água Subterrânea. Estado da Paraíba. Diagnóstico do Município de Pombal. Ministério de Minas e Energia. Recife, 2005.

BORTOLUZZI, D. L. Agroindústria familiar rural e desenvolvimento econômico: um estudo no município de doutor Maurício Cardoso/RS. Trabalho de Conclusão de Curso (TCC). Faculdade Horizontina, Horizontina, 2013. Disponível em: 
<http://www.fahor.com.br/publicacoes/TFC/Economia/2013/ Eco_Dinara.pdf>. Acesso em: 02 out. 2015.

BRASIL, CONAMA. Resolução $\mathrm{n}^{\circ}$ 430, de 13 de maio de 2011. Disponível em: <http://www.mma.gov.br/port/conama/legiabre.cfm?codlegi= 646>. Acesso em: 16 nov. 2015.

BRASIL, CONAMA. Resolução. 357, de 17 de março de 2005. Conselho Nacional do Meio Ambiente-CONAMA, v. 357, 2005. Disponível em: <www.mma.gov.br/port/conama/res/res05/res35705.pdf>. Acesso em: 14 nov. 2015.

CARDOSO, M. L.; PERALTA, A. H.; DE OliVEIRA, D. M. C.; COSTANZI, R. N. Remoção de nutrientes e matéria orgânica de efluente de laticínio por sistema alagado construído híbrido em Londrina-Paraná. Revista Hipótese, 1, 2015.

CARVALHO, D. L. D.; SOUZA, M. A. C. D.; ZEMPULSKI, D. A. Utilização do Método Eletrofoculação para tratamento de efluentes industriais. Revista Nacional de Gerenciamento de Cidades, 3, 2015.

CARVALHO, M. de. O que é natureza. Editora Brasiliense: Coleção Primeiros Passos. 2. ed. São Paulo, 2003.

CETESB. Companhia Ambiental do Estado de São Paulo. Significado ambiental e sanitário das variáveis de qualidade das águas e dos sedimentos e metodologias analíticas e de amostragem. 2009. Disponível em: $<$ http://cetesb.sp.gov.br/aguas-interiores/wpcontent/uploads/sites/32/2013/11/variaveis.pdf $>$. Acesso em 15 out. 2015.

CHEN, C.; HAN, G.; HE, H.; WESTCOTT, M. Yield, protein, and remobilization of water soluble carbohydrate and nitrogen of three spring wheat cultivars as influenced by nitrogen input. Agronomy journal, v. 103, n. 3, p. 786-795, 2011.

COELHO, D. S.; SIMÕES, W. L.; MENDES, A. M. S.; DANTAS, B. F.; RODRIGUES, J. A. S.; DE SOUZA, M. A. Germinação e crescimento inicial de variedades de sorgo forrageiro submetidas ao estresse salino. R. Bras. Eng. Agríc. Ambiental, 18, 2014. 25-30.

EDWIGES, T.; BOLLMANN, H. A. Avaliação temporal da carga orgânica transportada no Rio Belém, estação Prado Velho, Curitiba/PR, em eventos de chuvas. XVII Simpósio Brasileiro de Recursos Hídricos. São Paulo, 2007.

EMATER-PB. Registros Pluviométricos 2012-2015. Escritório Emater Pombal, 2015.

FABBI, L. M.; FRANÇA, R. G.; TOMAZELLI, I. B.; FILIPINI, T. A. Monitoramento de efluentes em agroindústrias de Chapecó, Santa Catarina. Revista de Ciências Ambientais, 1, p-67. 2011.

FILHO, R. J.; REIS., C. D.; SILVA, R. G. D. Cenários para o leite e derivados na Região Nordeste em 2020, SEBRAE, Recife, 2013.

GOMES, S. R. C.; DE SOUZA, S. M. T.; SANTANA, A. F.
B. Análise de um Sistema de Gestão Ambiental (SGA) em uma Indústria de Laticínios do Município de Ji-Paraná-RO. Revista Eletrônica Saber Contábil-RSC, 1, 2012. 18-34.

IBGE. Estatística da Produção Pecuária Junho de 2015. Brasília: IBGE, 2015.

JANCZUKOWICZ, W.; ZIELIŃSKI, M.; DĘBOWSKI, M. Biodegradability evaluation of dairy effluents originated in selected sections of dairy production. Bioresource Technology, 99, 2008. 4199-4205.

LIMA, J. O. G. D.; FRANÇA, A. M. M.; LOIOLA, H. G. Implicações hidroquímicas da condutividade elétrica e do íon cloreto na qualidade das águas subterrâneas do semiárido cearense. Revista Virtual de Química, 6, 2013a. 279-292.

MACHADO, R. M. G.; FREIRE, V. H.; SILVA, P. C.; FIGUERÊDO, D. V.; FERREIRA, P. E. Controle ambiental nas pequenas e médias indústrias de laticínios. 1 ed. Belo Horizonte: Segrac, 2002, 223 p.

MENDES, P. R. A.; FARIA, L. F. F. Avaliação do uso de processos de separação por membranas em efluentes de laticínios pré-tratados por coagulação/floculação. Blucher Chemical Engineering Proceedings, 1, 2015. 15084-15091.

MENDES, P. R. A.; FARIA, L. F. F. Avaliação do uso de processos de separação por membranas em efluentes de laticínios pré-tratados por coagulação/floculação. Blucher Chemical Engineering Proceedings, 1, 2015. 15084-15091.

MENDONÇA, H. V. D.; RIBEIRO, C. B. D. M.; BORGES, A. C.; BASTOS, R. R. Sistemas Alagados Construídos em Batelada: remoção de Demanda Bioquímica de Oxigênio e regulação de $\mathrm{pH}$ no tratamento de efluentes de laticínios. Revista Ambiente \& Água, 10, 2015. 442-453.

MENDONÇA, H. V. D.; RIBEIRO, C. B. D. M.; BORGES, A. C.; BASTOS, R. R. Remoção de nitrogênio e fósforo de águas residuárias de laticínios por sistemas alagados construídos operando em bateladas. Revista Ambiente \& Água-An Interdisciplinary Journal of Applied Science, v.7, 2012.

MOURA, E. M. Avaliação da disponibilidade hídrica e da demanda hídrica do trecho do rio Piranhas-Açú entre os açudes Coremas-Mãe D’água e Armando Ribeiro Gonçalves. Dissertação (mestrado). Universidade Federal do Rio Grande do Norte. Natal, 2007.

MÜLLER, L. R.; PARUSSOLO, L. Qualidade microbiológica da água utilizada para consumo em escolas municipais de Mamborê, Paraná. SaBios-Revista de Saúde e Biologia, 9, 2014. 95-99.

NAIME, R. H.; CARVALHO, S.; NASCIMENTO, C. A. Avaliação da qualidade da água utilizada nas agroindústrias familiares do vale dos sinos. Revista em Agronegócios e Meio Ambiente, v.2, n.1, p. 105-119, jan./abr. 2009 - ISSN 1981-9951.

OLIVEIRA, A. B. D.; ALENCAR, N. L. M.; PRISCO, J. T.; GOMES-FILHO, E. Accumulation of organic and inorganic solutes in $\mathrm{NaCl}$-stressed sorghum seedlings from aged and 
primed seeds. Scientia Agricola, 68, 2011. 632-637.

OLIVEIRA, F. D. A. D.; MARTINS, D. C.; OLIVEIRA, M. K. T. D.; NETA, M. L. D. S.; SILVA, R. T. D. Desenvolvimento inicial de cultivares de abóboras e morangas submetidas ao estresse salino. Revista Agro@mbiente On-line, 8, 2014. 222-229.

PÁDUA, H. B. Águas com dureza e alcalinidade elevadas conceitos e comportamentos ambientais observações iniciais na Região de Bonito/MS. 2001. Disponível em: <www.abrappesq.com.br/apostila_helcias.doc>. Acesso em 15 set. 2015.

RAMASAMY, E. V.; ABBASE, S. A. Energy recovery from dairy wastewaters: impacts of biofilm support system on anaerobic CST reactors. Applied Energy. n. 65, 2000. p. 9198.

ROCHA, F. C.; ANDRADE, E. M.; LOPES, F. B. Water quality index calculated from biological, physical and chemical attributes. Environmental monitoring and assessment, 187, 2015. 1-15.

ROSSETTI, R. P. Evolução da carga orgânica de origem doméstica no rio Paraíba do Sul, no trecho paulista, no período de 1998 a 2007. Tese de Doutorado. Universidade de São Paulo. São Paulo, 2009.

SANTOS, J. O. D., SANTOS, R. M. D. S., GOMES, M. A. D., MIRANDA, R. C. D. \& NÓBREGA, I. G. D. M. A qualidade da água para o consumo humano: Uma discussão necessária. Revista Brasileira de Gestão Ambiental, 7, 2013. 19-26.
SARAIVA, C. B. Potencial poluidor de um laticínio de pequeno porte: um estudo de caso. Dissertação (Mestrado) Universidade Federal de Viçosa. Viçosa, 2008. Disponível em: <http://www.tede.ufv.br/tedesimplificado/tde_arquivos/39/T DE-2009-06-19T075605Z-

1692/Publico/texto\%20completo.pdf>. Acesso em: 19 out. 2015.

SILVA, A. M. M. D.; SACOMANI, L. B. Using chemical and physical parameters to define the quality of Pardo River water (Botucatu-SP-Brazil). Water Research, 35, 2001. 16091616.

UNWWAP, U. N. W. W. A. P. The United Nations World Water Development Report 2015: Water for a Sustainable World. United Nations Educational, Scientific and Cultural Organization Paris, France, 2015.

VASCONCELOS, A. V.; SILVA, M. R. D. Avaliação físicoquímica e microbiológica da qualidade da água de pequenos laticínios da região de Francisco Beltrão/PR. Trabalho de Conclusão de Curso (Graduação) - Curso Superior de Tecnologia em Alimentos. Universidade Tecnológica Federal do Paraná, Francisco Beltrão, 2013.

VON SPERLING, M. Introdução à qualidade das águas e ao tratamento de esgotos. Belo Horizonte, Editora UFMG, 2014.

WETZEL, R. G. References Cited. In: WETZEL, R. G. (ed.) Limnology (Third Edition). San Diego: Academic Press, 2001. 